\title{
Are Hospital Efficiency and Quality of Care Affordable Without External Revenue?
}

\author{
Frank Pieter M. Naus \\ Hamilton, Ontario, Canada \\ Carol-Anne Faint \\ Walden University \\ Rocky J. Dwyer \\ Walden University
}

This qualitative study explored strategies academic research hospital administrators in Ontario, Canada, apply to generate nongovernment revenue to remain sustainable. The participants in the study consisted of senior-level academic research hospital executives with extensive experience in the subject area from major academic research hospitals, ranking the hospitals from highest to lowest in revenue generation. From this study, five themes emerged: working within the fiscal reality, the impact of the political environment, the focus on the mission, nongovernment revenue generation, and opportunities for the Ontario academic research hospitals. Findings from this study may contribute to discussions on implementing change by encouraging hospital executives to adopt a more coordinated and consistent approach to generating nongovernment revenue to support the mission of their hospitals.

Keywords: academic research hospital funding, external revenue generation, health care, health care cost, nongovernment revenue generation, quality of care affordability

\section{Introduction}

Health care in Canada is considered a right, in contrast to the United States, where health care is considered a privilege (Bhatia \& Orsini, 2016). Gettings et al. (2014) confirmed the negative perception toward commercial activity within the field of medicine in Canada. Several researchers focused on how systems improvement can benefit patient care (Ouyang, Stephen, \& Spohrer, 2013; Singh, Wheeler, \& Roden, 2012), while others developed theses predicated on changing the Canada Health Act (1985) to allow privatization of health care to further generate revenue (Sutherland, Crump, Repin, \& Hellsten, 2013). French and Miller (2012) discussed the emergence of the entrepreneurial hospital but defined it as a hospital that conducted research for commercial purposes. Most promising is the literature related to innovation providing a means to explore revenue opportunities within the existing system, but very little of this work focused on revenue generation (Marchildon, Verma, \& Roos, 2013; Strumpf et al., 2012). Little research regarding sources of revenue within the Canadian health care system is available, and what research exists is generally negative (Duggal, 2008).

Health care administrators in Ontario, Canada, want to transform health care with a focus on improving efficiency and quality of care, yet they tend to overlook increasing revenue (Collier, 2011) as part of the solution. Hospitals clearly need Canada Health Act-compliant, nongovernment sources 
of revenue, particularly when health care consumes $42 \%$ of the total provincial budget (Duncan, 2012). Hospital executives are uncertain how to increase revenue, yet financial constraints are forcing them to reduce costs or find new sources of revenue (Stabile \& Thomson, 2014). Ontario hospital administrators lack strategies to generate nongovernment revenue to remain sustainable.

In this article, theoretical constructs are critical to understanding the hospital, provincial, and Canadian health care systems. The theoretical constructs used include organizational transformation, leadership, and the history of evidence-based change. Specifically, implementing change in these systems involves entities employing thousands of individuals, including some of the most highly educated members of society, and operating across decades if not centuries. Within the complex system, leaders must find ways to motivate and create the environment for change. The conceptual framework guiding the study was radical organizational change theory (Lee, Weiner, Harrison, \& Belden, 2013), supported by complexity leadership theory (Weberg, 2012), and grounded in an evidence-based approach (Eddy et al., 2011; Smith \& Rennie, 2014).

The modern hospital in Ontario is a complex organization requiring sophisticated organizational approaches to systems change. Lee et al. (2013) described radical organizational change that occurs when the external conditions and internal dynamics of an organization interact under the influence of changing market conditions, changing institutional conditions, and declining organizational performance leading to friction between stakeholders. The complex interplay of factors described by Lee et al. (2013) directly applies to the situation facing Ontario academic research hospitals, and therefore provides a solid conceptual framework for this study.

Furthermore, we acknowledge the impact of leadership on the Ontario academic research hospital and the ability of both to evolve. Complexity leadership theory (Weberg, 2012) best describes leadership in a complex health care organization with minimal control and structure. Understanding effective leadership within the hospital requires a shift away from leader-centric thinking and a move toward collaboration, problem solving, innovation, and other outcomes leading to successful adaptation (Weberg, 2012).

Administrators, staff, and, to some extent, the public in Canada, frame change within the public health care system through the lens of an evidence-based approach. The concepts pioneered by Eddy et al. (2011) and the Evidence-Based Medicine Working Group (Smith \& Rennie, 2014) are firmly ingrained in Canadian medical and hospital culture to the point that changes proposed without supporting evidence rarely succeed. The conceptual framework of using evidence to guide practice provides the foundation for the approach to the study of nongovernment revenue generation in the Ontario hospital. The process of creating evidence involves analyzing research and developing guidelines. Groups sponsored by an organization, using an explicit, rigorous process, develop a generic approach (applies to a class or group) that becomes a guideline. The ultimate effects of these guidelines are indirect (Eddy et al., 2011). The evidence-based approach, when applied to revenue generation, facilitates the acceptance of the new concepts within the hospital community. The purpose of this qualitative case study is to explore strategies Ontario hospital administrators use to generate nongovernment revenue to remain sustainable (Laxton \& Yaya, 2013).

\section{Research Methodology and Design}

This article explores nongovernment revenue strategies in academic research hospitals in Ontario through a qualitative approach allowing for the interpretation and the justification in a public forum, ideally leading to change and further research (Merriam, 2014). Senior-level academic 
research hospital executives with extensive experience in the subject area from large- and mediumsized hospitals participated in study. The research study parameters included field observations and a review of public and private sources of documentation including audited institutional financial statements.

\section{Conceptual Framework}

Constructing the conceptual framework for this study required a careful understanding of the issues affecting the existing state of Ontario's academic research hospitals. A number of theoretical constructs are critical to understanding the hospital and the health care system, including organizational transformation, leadership, and the history of evidence-based change.

The conceptual framework guiding this study was radical organizational change theory (Lee et al., 2013), supported by complexity leadership theory (Weberg, 2012) and grounded in an evidence-based approach (Eddy et al., 2011; Smith \& Rennie, 2014).

The modern hospital in Ontario is a complex organization requiring sophisticated organizational approaches to systems change. Lee et al. (2013) described radical organizational change that occurs when the external conditions and internal dynamics of an organization interact under the influence of changing market conditions, changing institutional conditions, and declining organizational performance (leading to friction between stakeholders). The complex interplay of factors described by Lee et al. (2013) directly applied to the situation facing Ontario academic research hospitals, and therefore provided a solid conceptual framework for this study.

In addition, complexity leadership theory by Weberg (2012) best described leadership in a complex health care organization with minimal control and structure. Understanding effective leadership within the hospital required a shift away from leader-centric thinking and a move toward collaboration, problem solving, innovation, and other outcomes leading to successful adaptation. Administrators, staff, and, to some extent, the public in Canada framed change within the public health care system through the lens of an evidence-based approach. The concepts pioneered by Eddy et al. (2011) and the Evidence-Based Medicine Working Group (Smith \& Rennie, 2014) appear deeply ingrained within the Canadian medical and hospital cultures to the point where changes proposed without supporting evidence rarely succeed. The conceptual framework of using evidence to guide practice provided the foundation for the approach to this study of nongovernment revenue generation in the Ontario hospital research system. The process of creating evidence involved analyzing research and developing guidelines. Groups sponsored by an organization, using an explicit, rigorous process, developed a generic approach (applies to a class or group) that becomes a guideline; thus, the ultimate effects of these guidelines were indirect. The evidence-based approach, when applied to revenue generation, facilitated the acceptance of the new concepts within the hospital community. Radical organizational change theory, complexity leadership, and evidencebased medicine were foundational concepts for the study. Positively impacting the financial performance of Ontario's academic research hospitals required understanding the system through the three constructs. Changes placed appropriately within the concept of radical organizational change theory, carefully led by both medical and administrative hospital leaders, and supported by evidence, were critical in strengthening Ontario hospitals in a challenging fiscal environment.

\section{Health Care: A Canadian Perspective}

Health care in Canada, with health care defined as medically necessary hospital and physician services, ranked higher than in other Organization of Economic Cooperation and Development 
countries (Marchildon, 2013). However, as the cost drivers of health care continued to put pressure on the system (through increasing salaries and escalating use of prescription drugs), and as government budgets continued to shrink, there have been increasing pressures on health care organizations to find cost reductions or nongovernment sources of revenue (Duncan, 2012; Marchildon, 2013).

While Canadians have the advantage of universal Medicare, the meaning of universality within the literature requires further exploration. However, there are three recognized dimensions of universal Medicare: the population covered, the costs covered, and the health services covered. Marchildon (2014) noted that for Canadians, universal coverage was complete with respect to the population and expenses covered but limited in terms of what health services were covered (for example, acute care is covered, but home care and prescription drugs were not covered). Delivering value in Medicare meant optimizing quality, service, and cost (Makadon, Bharucha, Gavin, Oliviera, \& Wietecha, 2010). Webster (2012) argued that the Canadian health care system was disorganized and expensive, as well as substandard and archaic. Webster noted that a reluctance to reform the system existed, resulting in little evolution since the 1970s. Although Canadians believed that Canada's health care system protects them, those experiencing financial difficulty still faced unaffordable out-of-pocket costs (Himmelstein et al., 2014).

\section{Controlling Cost}

Pushing against cost containment in universal health care were efforts at expanding the base of health care and concerns regarding the quality of care. Sutherland et al. (2013) discussed the potential role of financial incentives for funding public health care, including activity-based funding. The authors acknowledged that budget pressures were focusing policymakers on funding models that emphasize quality and outcomes at the lowest possible cost. Another concern regarding universal care was the quality of care. Brzezinski (2009) compared the U.S. and British health care systems and found no studies providing a direct comparison of the systems-systems with both triumphs and flaws. Nevertheless, the author noted a global trend in favor of universal health care (Brzezinski, 2009). Perhaps the focus for Canada's health care system should be on providing the best value for its citizens (Blomqvist \& Busby, 2012). Part of providing value involved controlling costs.

\section{Sustainability}

Sustainability in an environment where ongoing government support was flat or shrinking is the challenge Ontario hospitals face. Gamble (2012) highlighted eight issues hospital administrators must consider: (a) Were physicians aligned with the hospital's strategy? (b) Did the hospital deliver high-quality care? (c) Did the hospital have a strong leadership team? (d) Was there a clear operating plan? (e) Was there a compelling reason for the hospital to exist? (f) Was the hospital known for something? (g) What was the payer mix (applicable to U.S. hospitals)? (h) Was the hospital large enough to withstand the risk of opportune investments? Similar questions regarding the financial sustainability of universal care in Canada were important. Laxton and Yaya (2013) estimated that, by 2030 , Ontario's health care costs will represent $80 \%$ of the provincial budget and argued for alternative funding strategies. Sustainability required innovative and diverse strategies. Strumpf et al. (2012) noted Canada's focus on improving targeted organizational infrastructure, provider payment structures, the health care workforce, and quality and safety initiatives as drivers of positive change. The reforms were voluntary, incremental, and diverse and encouraged engagement and participation by multiple stakeholders. The reforms highlighted the focus on sustainability in health care. 


\section{Patient Perspective and Social Responsibility}

An important consideration when implementing change in the health care system was the perspective of the patient and the concept of social responsibility. Detsky (2012) listed nine highlevel priorities: restoring health when ill, timeliness, kindness, hope and certainty, continuity/choice/coordination, private rooms, no out-of-pocket expenses, the best medicine, and medications and surgeries. The mid-level priorities included efficiency, aggregate-level statistics, equity, and conflicts of interest, and the low-priority items were identified as the real cost and percentage of gross national product devoted to health care (Detsky, 2012). Essentially, sick people want to feel better and remain unconcerned regarding the length of the recovery period if they have no responsibility for hospital stay costs or incur no out-of-pocket expenses related to the hospital stay.

Recognizing that structural changes continued to occur in health care, Collier (2011) recognized that the system needed new revenue streams. Clearly, the literature demonstrates that a desire to improve the system exists, as well as recognizing the need for comprehensive systemic changes. However, little research focused on how institutions generate revenue in support of their operations. Most of the focus appeared to be on controlling costs within Ontario's complex academic research hospitals and within the health care system more generally. The systems approach required complex systemic and political changes. However, the question remains as to what hospitals should do while waiting for changes to occur. The answer lay in generating revenue in a complementary fashion.

\section{Research Finding and Analysis}

From the interviews and other supporting documentation, it is evident that hospital executives must actively pursue revenue generation as part of a strategy to sustain their hospital. As well, the research revealed five themes: (a) working within the fiscal reality, (b) the impact of the political environment, (c) the focus on the mission, (d) nongovernment revenue generation, and (e) opportunities for the Ontario academic research hospital, which leaders must consider in developing sustainable solutions. Specifically, leaders must embrace nongovernment revenue as an important strategy, must actively promote the strategy both individually and collectively, and must capitalize on unused capacity within the health care system. Only by focusing on sustainable solutions will we maintain health care as a right (Bhatia and Orsini, 2016), change public perception regarding commercial activity in health care (Gettings et al., 2014), strengthen the Canada Health Act through changes enabling revenue generation (Sutherland et al., 2013), and address the lack of research on revenue generating activities occurring within the system.

We invited all participants to provide relevant material (website, print, etc.) regarding nongovernment revenue generation; each declined citing the unfortunate need to draw as little attention as possible to these activities. Our review of published hospital financial statements yielded little information regarding nongovernment revenue generation other than activities that are standard at all hospitals (food services, parking, etc.).

During the interviews, each of the interviewed senior leaders discussed all five of the identified themes. The consistency of answers with respect to the five themes suggested the conceptual framework and the interview questions enabled the effective identification of the relevant themes during the interview process. 


\section{Theme 1: Working Within the Fiscal Reality}

Leaders of Ontario academic research hospitals face a difficult fiscal reality. Sutherland et al. (2013) acknowledged that budget pressures are focusing policymakers on funding models that emphasize quality and outcomes at the lowest possible cost. The pressure to achieve quality and outcomes at the lowest possible cost was evident in the responses of all leaders interviewed. All participants discussed the mandate of the Ontario academic research hospital, the mandate to provide care, education, and research. At the same time, all participants emphasized the pressure from government to reduce cost and a simultaneous pressure from the communities served by the hospital to provide full service. The challenge to achieve full service in care, education, and research, while reducing cost, all within the context of a large, complex organization is daunting.

The fiscal reality described by hospital executives requires radical organizational change (Lee et al., 2013) supported by competent leaders applying complexity leadership theory (Weberg, 2012), and supported by evidence (Eddy et al., 2011; Smith \& Rennie, 2014). All leaders described a system in which they had cut costs as much as possible. Subsequent substantive change requires new thinking and new approaches, as traditional approaches are exhausted and no longer effective. The fiscal reality executives' face requires collaborative, problem-solving approaches to the fiscal reality of the academic research hospital (Weberg, 2012) and a move beyond theory to active lobbying of government for budget relief and real systemic change, conducted through a consolidated effort by all hospital executives. Executives must take care to frame solutions within the context of an evidence base, lest they fall into the same trap as politicians proposing changes that are merely politically attractive.

\section{Theme 2: The Impact of the Political Environment}

The political environment in the single-payer system that funds the Ontario academic research hospital affects it directly. For the purpose of this article, the political environment includes public perception, as described by the study participants, and its impact on the hospital. All leaders indicated that public perception and the political environment played a significant role in what issues they were willing to address. This reality creates a layer of complexity to which business leaders can be less sensitive. As well, the hospital executives expressed that there are strategies that were potentially beneficial to the hospital in which they cannot engage. For example, there were tremendous sensitivities in caring for non-Canadian residents; the public perceived any hint of queue-jumping (treatment in advance of other patients is provided to certain individuals, typically those with money, preferentially) negatively; the public was intolerant of displacing local patients; and for one hospital executive, there was public concern expressed regarding the hospital competing with the private sector.

The political reality described by hospital executives requires the active application of radical organizational change (Lee et al., 2013) that extends beyond the hospital and into the political realm. Leaders must engage in the political process and through lobbying and other efforts, effect change and address some of the issues described previously including under-utilized capacity. Applying complexity leadership theory (Weberg, 2012) along with an evidence-based approach (Eddy et al., 2011; Smith \& Rennie, 2014) allows executives to engage fully in processes that potentially lead to solutions to the crises facing Ontario academic research hospitals. Only by facing political reality can hospital leaders create the disruptive changes required to address the problems they face. 


\section{Theme 3: Mission}

A third theme consistently referred to by the participants was the focus on the mission of the hospital. Ontario academic research hospitals all have similar foci; the dedication to care typically comes first, followed closely by research and teaching. An academic research hospital, by definition, provides care that is (hopefully) evidence-based and supports the generation (research) and dissemination (teaching) of evidence.

The mission of the academic research hospital imposes restrictions that affect leaders' ability to generate nongovernment revenue. Executives must apply radical organizational change complexity leadership theory and evidence-based approaches to change, within the context of the academic research hospital mission. The mission and its impact on nongovernment revenue as described by leaders restrict the ability of leaders to be flexible. At worst, the mission limits options for change or revenue generation, and at best, it provides a framework for what is a reasonable change or revenue generating activity.

\section{Theme 4: Nongovernment Revenue Generation}

The fourth theme identified was nongovernment revenue generation in the hospital. All executives interviewed described nongovernment revenue generating activities occurring at their hospitals. Clearly, all executives saw the generation of nongovernment revenue as an important component of their mandate and the ability to generate revenue was critical to the hospital balance sheet.

All four of the executives suggested that the generation of nongovernment revenue was an important part of their mandate and their ability to run their hospital effectively. The challenge was how to maximize this revenue. Leaders must apply radical organizational change to ensure that stakeholders understand and accept nongovernment revenue to enhance the hospital as opposed to as a threat with the potential to disrupt the system - an approach support by Lee et al. (2013). Using the attributes identified in complexity leadership theory, and bolstered by evidence-based arguments, executives must maximize returns from activities they believe fulfill their mandate as leaders of academic research hospitals.

\section{Theme 5: Opportunities for the Ontario Academic Research Hospital}

The fifth theme identified in the interviews was that of opportunities for the Ontario academic research hospital. The leaders all recognized the importance of the limited nongovernment revenue generating activities in which their institutions participated and that the scope of these activities needed to increase to meet the demands of the hospital. Hospital executives must apply business principles to maximize revenue, within the mandate of their mission.

A majority of those interviewed recognized that new revenue streams, as described by Collier (2011), were critical for the Ontario academic research hospital. The executives each expressed a desire to improve the system and the functioning of their hospital, but as MacKinnon (2013) noted, changing or reforming the health care system in Canada is difficult. Balancing social and political sustainability (Borgonovi \& Compagni, 2013) amidst continuing cutbacks (Ruckert \& Labonté, 2014) creates difficult challenges for the hospital executive. The discussions with all leaders confirmed the findings in the literature with respect to controlling costs, the need for sustainable solutions, attitudes toward industry and the private/for-profit sector, and the awareness executives had regarding how hospitals generate revenue internationally. The perspective of the patient and the significant pull of social and corporate responsibility (Takahashi, Ellen, \& Brown, 2013) are also 
important for hospital leaders. All leaders universally expressed frustration at not being able to do more to generate nongovernment revenue to further the mission of the hospital.

The leaders interviewed provided a wealth of information regarding the Ontario academic research hospital and the challenges they, as leaders, faced. Many recommendations flowed logically from the interviews:

1. Executives must embrace nongovernment revenue generation as a viable and significant strategy to support hospital operations;

2. Executives must encourage government to not create roadblocks and interfere with the functioning of the hospital for political purposes;

3. Executives must create flexibility within their organizations to take advantage of nongovernment revenue generating opportunities;

4. Executives must recognize that politics are part of our health care system and must participate actively in the process to lobby on behalf of hospitals at provincial and national levels;

5. Executives must work to eliminate disincentives for revenue generation, including actively demonstrating how these activities positively affect care;

6. Executives must communicate to government that government must encourage appropriate nongovernment revenue generating activities as part of responsible stewardship of the hospital;

7. Executives must understand and communicate that the hospital mission is always paramount, but includes sustainability;

8. Executives must strengthen and build on their existing nongovernment-revenue-generating capabilities;

9. Executives must build and strengthen their hospital's brand within their communities (local, provincial, national, and international) and capitalize on that brand; and

10. Executives must capitalize on unused capacity within their institutions.

This article explored nongovernment revenue generation in Ontario academic research hospitals. Subsequent research should extend beyond the academic research hospital in Ontario to all academic research hospitals in Canada, and further work could include all Canadian hospitals (including community hospitals). Clearly, all hospitals benefit from receiving additional revenue and reducing their reliance on government, and examining a broader base provides insight into improving the entire system. We also suggest that quantitative research examining nongovernment revenue generation could provide important data on the magnitude of the contribution to hospital revenue possible. Unless we quantify the potential contribution, relative to the cost (both financial and human resource), it is difficult to determine whether these activities are worth pursuing. Additional research will help build the case for establishing a provincial or national entity to support these activities, which is necessary because hospital executives are experts at running a hospital; however, they are not experts at generating revenue. Finally, additional research regarding for-profit medical care delivered outside the 9-to-5 schedule of the hospital, but using the underutilized capacity that exists in the system, is also necessary. The sustainability of the Ontario academic research hospital requires both research and action.

\section{Conclusion}

Historically, health care administrators in Ontario attempted to transform health care with a focus on improving efficiency and quality of care, with little attention paid to increasing revenue (Collier, 2011). Sustaining a hospital requires Canada Health Act compliant, nongovernment sources of 
revenue. Unfortunately, hospital executives are uncertain how to increase revenue while financial constraints force them to reduce costs (Stabile \& Thomson, 2014). Some Ontario hospital administrators lack strategies to generate nongovernment revenue to remain sustainable (Laxton \& Yaya, 2013), which this research now provides.

Hospital executives must actively pursue revenue generation as part of a strategy to sustain their hospital. Our research revealed five themes: (a) working within the fiscal reality, (b) the impact of the political environment, (c) the focus on mission, (d) nongovernment revenue generation, and (e) opportunities for the Ontario academic research hospital, which leaders must consider in developing sustainable solutions. More specifically, leaders must embrace nongovernment revenue as an important strategy, must actively promote the strategy both individually and collectively, and must capitalize on unused capacity within the health care system. Only by focusing on sustainable solutions will we maintain health care as a right (Bhatia \& Orsini, 2016), change public perception regarding commercial activity in health care (Gettings et al., 2014), strengthen the Canada Health Act through changes enabling revenue generation (Sutherland et al., 2013), and address the lack of research on revenue generating activities occurring within the system.

Hospital executives could greatly improve the fiscal reality facing academic research hospitals through the utilization of nongovernment sources of revenue while staying true to the commitments of the Canada Health Act. The infrastructure is in place; the population understands the need to generate revenue and is clearly unprepared to pay more taxes, and now we need the political will.

\section{References}

Bhatia, V., \& Orsini, M. (2016). Narrating sustainability in Canadian health care reform discourse. Social Policy and Administration, 50, 297-315. doi:10.1111/spol.12103

Blomqvist, Å., \& Busby, C. (2012, January 31). Better value for money in healthcare: European lessons for Canada (C. D. Howe Institute Commentary No. 339). doi:10.2139/ssrn.2021330

Bloomberg, L. D., \& Volpe, M. (2012). Completing your qualitative dissertation: A road map from beginning to end. Thousand Oaks, CA: Sage.

Borgonovi, E., \& Compagni, A. (2013). Sustaining universal health coverage: The interaction of social, political, and economic sustainability. Value in Health, 16, S34-S38. doi:10.1016/j.jval.2012.10.006

Brzezinski, N. (2009). Does a universal health care system cause a decrease in quality of care? A comparison of American and British quality in primary care. The Internet Journal of Academic Physician Assistants, 6, 2. Retrieved from https://ispub.com/IJAPA/6/2/11138

Canada Health Act, R.S.C., c. C-6 (1985). Retrieved from http://laws-lois.justice.gc.ca/PDF/C-6.pdf

Collier, R. (2011). Health care system needs new revenue streams, expert argues. Canadian Medical Association Journal, 183, E989-E990. doi:10.1503/cmaj.109-3975

Detsky, A. S. (2012). How to control health care costs. Journal of General Internal Medicine, 27, 1095-1096. doi:10.1007/s11606-012-2075-8

Duggal, S. (2008). Viewing patients as "sources of revenue." Canadian Medical Association Journal, 178, 817. doi:10.1503/cmaj.080294

Duncan, D. (2012). 2012 Ontario economic outlook and fiscal review: 2012 background papers. Retrieved from http://www.fin.gov.on.ca/en/budget/fallstatement/2012/ 
Eddy, D. M., Adler, J., Patterson, B., Lucas, D., Smith, K. A., \& Morris, M. (2011). Individualized guidelines: The potential for increasing quality and reducing costs. Annals of Internal Medicine, 627-634. doi:10.7326/0003-4819-154-9-201105030-00008

French, M., \& Miller, F. A. (2012). Leveraging the "living laboratory": On the emergence of the entrepreneurial hospital. Social Science \& Medicine, 75, 717-724. doi:10.1016/j.socscimed.2012.04.010

Gamble, M. (2012, May 18). Is your hospital sustainable? 8 questions to ask. Becker's Hospital Review. Retrieved from http://www.beckershospitalreview.com/hospital-managementadministration/is-your-hospital-sustainable-8-questions-to-ask.html

Gettings, J., O’Neill, B., Choksi, D. A., Colbert, J. A., Gill, P., Lebovic, G., ... Persaud, N. (2014). Differences in the volume of pharmaceutical advertisements between print general medical journals. PLoS ONE, 9, e84790. doi:10.1371/journal.pone.0084790

Himmelstein, D. U., Jun, M., Busse, R., Chevreul, K. Geissler, P. J., Thomson, S., ... Woolhander, S. (2014). A comparison of hospital administration costs in eight nations: U.S. costs exceed all others by far. Health Affairs, 33, 1586-1594. doi:10.1377/hlthaff.2013.1327

Laxton, S., \& Yaya, S. (2013). The demand for alternative forms of financing universal health care in Canada: A literature review. Interdisciplinary Journal of Health Sciences, 3, 32-36.

Lee, S. D., Weiner, B. J., Harrison, M. I., \& Belden, C. M. (2013). Organizational transformation: A systematic review of empirical research in health care and other industries. Medical Care Research and Review, 70, 115-142. doi:10.1177/1077558712458539

MacKinnon, J. (2013, January). Health care reform from the cradle of Medicare. Retrieved from http://www.macdonaldlaurier.ca/files/pdf/Health-Care-Reform-From-the-Cradle-of-MedicareJanuary-2013.pdf

Makadon, H. J., Bharucha, F., Gavin, M., Oliviera, J., \& Wietecha, M. (2010). Value management: Optimizing quality, service, and cost. Journal for Healthcare Quality, 32, 29-34.

Marchildon, G. P. (2013). Canada: Health system review. Health Systems in Transition, 15, 1-179. Retrieved from http://www.hpi.sk/cdata/Documents/HIT/Canada_2013.pdf

Marchildon, G. P. (2014). The three dimensions of universal Medicare in Canada. Canadian Public Administration, 57, 362-382. doi:10.1111/capa.12083

Marchildon, G. P., Verma, J. Y., \& Roos, N. (2013). The science and art of combining evidence with opinion. BMJ Evidence-Based Medicine, 18, 161-164. doi:10.1136/eb-2012-100996

Merriam, S. B. (2014). Qualitative research: A guide to design and implementation. San Francisco, CA: John Wiley \& Sons.

Ouyang, Q. C., Stephen, P., \& Spohrer, J. (2013, January). Collaborative innovation center as a new service system to drive economic development. In 2014 International Conference on Global Economy, Commerce and Service Science (GECSS-14) (pp. 382-387). Amsterdam, The Netherlands: Atlantis Press. doi:10.2991/gecss-14.2014.96

Ruckert, A., \& Labonté, R. (2014). The global financial crisis and health equity: Early experiences from Canada. Globalization and Health, 10, 1-10. doi:10.1186/1744-8603-10-2

Singh, S. R., Wheeler, J., \& Roden, K. (2012). Hospital financial management: What is the link between revenue cycle management, profitability, and not-for-profit hospitals' ability to grow equity? Journal of Healthcare Management, 57, 325-339. 
Smith, R., \& Rennie, D. (2014). Evidence-based medicine: An oral history. JAMA, 311, 365-367. doi:10.1001/jama.2013.286182

Stabile, M., \& Thomson, S. (2014). The changing role of government in financing health care: An international perspective. Journal of Economic Literature, 52, 480-518. doi:10.1257/jel.52.2.480

Strumpf, E., Levesque, J. F., Coyle, N., Hutchison, B., Barnes, M., \& Wedel, R. J. (2012). Innovative and diverse strategies toward primary health care reform: Lessons learned from the Canadian experience. Journal of the American Board of Family Medicine, 25, S27-S33. doi:10.3122/jabfm.2012.02.110215

Sutherland, J. M., Crump, R. T., Repin, N., \& Hellsten, E. (2013). Paying for hospital services: A hard look at the options (C.D. Howe Institute Commentary No. 378). Retrieved from http://www.cdhowe.org/pdf/Commentary_378.pdf

Takahashi, T., Ellen, M., \& Brown, A. (2013). Corporate social responsibility and hospitals: U.S. theory, Japanese experiences, and lessons for other countries. Healthcare Management Forum, 26, 176-179. doi:10.1016/j.hcmf.2013.07.003

Weberg, D. (2012). Complexity leadership: A healthcare imperative. Nursing Forum, 47, 268-277. doi:10.1111/j.1744-6198.2012.00276.x

Webster, P. C. (2012). Can Canada reckon with its health costs? The Lancet, 380, 875-876. doi:10.1016/S0140-6736(12)61490-1

The International Journal of Applied Management and Technology (IJAMT), sponsored by Walden University's School of Management, is a peer-reviewed, online journal that addresses contemporary national and international issues related to management and technology. The objectives of the IJAMT are to: (a) encourage collaborative and multi-disciplinary examinations of important issues in business and technology management, and (B) engage scholars and scholar-practitioners in a dynamic and important dialogue.

Walden University Publishing: http://www.publishing.waldenu.edu 